\section{Orlando Oscar Rosar}

Professor Assistente da Universidade Federal do Maranhão, Doutorando

- UNICAMP. Instituto de

Economia (IE).

\title{
A teoria de Minsky no atual contexto
}

\section{I - Pressupostos teóricos de Minsky}

Minsky desenvolveu sua teoria buscando explicar os determinantes da instabilidade financeira de maneira que permitisse elucidar as razões das flutuações na economia. Nessa perspectiva, o autor afirma que o comportamento diferenciado da economia nos diferentes períodos está relacionado com a variação nas práticas financeiras e na estrutura de compromissos financeiros. As práticas financeiras são decorrentes das obrigações contratuais que refletem as condições de mercado e as expectativas predominantes quando os contratos foram negociados e assinados (MINSKY, 1986:197).

Os contratos são negociados e assinados sob as condições de incerteza que caracterizam o ambiente econômico no qual os agentes vivem. Nessa condição de incerteza, verifica-se a mudança de comportamento e estabilidade da economia, como também a alteração da relação do pagamento de obrigações contratuais com fundos disponíveis para tal fim, fazendo com que os arranjos financeiros possam se desenvolver.

A origem dessas mudanças está diretamente relacionada com o surgimento de oportunidades de lucro abertas pelas inovações financeiras, dentro de um dado tipo de instituições e regras; um caminho para inovar as práticas financeiras em busca de lucro por famílias, empresários e banqueiros; e intervenções legislativas e administrativas por governos e bancos centrais (MINSKY, 1986:197).

Minsky procura demonstrar que os novos arranjos institucionais, principalmente os novos produtos financeiros, caracterizam-se sobretudo como resposta ao controle das Autoridades Monetárias. Essas inovações fazem aumentar o volume de financiamento disponível, através da criação endógena de moeda e quase moeda, uma vez que os bancos fornecem recursos para o financia- mento do comércio e dos investimentos de posições em ativo de capital.

Para entender como as relações financeiras afetam a economia, se faz necessário observar as unidades econômicas no que diz respeito a seus fluxos de caixa, uma vez que a não sincronia entre o pagamento de débitos contratuais e as receitas operacionais pode surgir na relação banco-empresas, quando posições em ativos de longo prazo são financiadas por passivos de curto prazo (COSTA, 1994:158).

Minsky introduz os passivos na discussão. Além da estrutura dos ativos, interessa também como os mesmos são financiados, o que possibilita verificar a composição dos passivos. Neste sentido, cada unidade econômica é caracterizada pela maneira como em seu portfólio sincroniza de forma a compatibilizar datas e valores de pagamentos com 
datas em que espera receita suficiente para cumpri-los.

Ao abordar a composição do portfólio, Minsky demonstra que a incerteza participa tanto nas decisões das famílias, firmas e instituições financeiras, quanto nas perspectivas tomadas pelas firmas, pelos proprietários de ativos de capital, e pelos banqueiros na fixação dos retornos esperados das suas aplicações.

Havendo uma elevação demasiada da taxa de juros reais (mesmo quando comparada com os preços) e o retorno líquido do capital não crescendo na mesma proporção, verifica-se um agravamento da fragilidade financeira, pois altera-se a relação entre o custo da dívida e o retorno esperado. A capacidade do devedor efetuar os pagamentos decorrentes dos contratos está relacionada com o volume de vendas, grau de endividamento, prazo da dívida, taxa de juros, correção cambial e correção monetária.

A maior elasticidade na geração de recursos pelo sistema financeiro está em função das margens de garantia e das expectativas favoráveis quanto ao comportamento dos lucros agregados. Por seu turno, o aumento do grau de endividamento das empresas não financeiras reflete a perspectiva de refinanciamentos no curto prazo, além de uma expectativa otimista no longo prazo. Assim, o autor incorpora tanto os riscos do credor quanto do devedor à análise das decisões de investimento. O risco do devedor está relacionado à incerteza quanto ao retorno do próprio ativo financiado na com- pra, enquanto o risco do credor envolve a incerteza (do devedor) e mais o risco do devedor não fazer os pagamentos das obrigações estipuladas em contrato. $\mathrm{Na}$ verdade o credor incorre em duplo risco. Este risco tem que ser compensado não somente com a taxa de juros imposta em cada contrato, além do encurtamento dos prazos, mas também, com uma determinada margem de segurança, através de um ativo em garantia.

Numa economia com tomadores e emprestadores, em que os primeiros contraem empréstimos para investimentos, em função de suas expectativas de retorno dos ativos que são incertas, enquanto os pagamentos dos passivos contratados tornamse certos, o tomador sofre sanções, correndo o risco da falência, com provável exclusão do mercado de crédito. Desse tipo de operação advém a fragilidade financeira, fazendo com que haja um certo grau de precaução dos agentes econômicos que constituem um sistema financeiro, quer por critério de liquidez ou de solvência.

Com um desempenho econômico favorável e altas taxas de retorno sobre o capital aplicado, gera-se uma situação de expectativas amplamente positivas. A diminuição dos riscos na avaliação tanto de credores quanto de devedores propicia um "boom" de investimentos, sustentados por criação endógena de dinheiro, através da amplificação do crédito junto aos bancos. O bom desempenho da economia e o clima de estabilidade financeira, faz com que as margens de garantias exigidas pelos bancos te- nham a tendência de ser reduzidas e o grau de alavancagem financeira das empresas não-financeiras seja ampliado, pois o risco do financiamento externo face ao uso de recursos próprios é subestimado.

Havendo elevação do fluxo de caixa, para cumprir contratos financeiros em relação ao fluxo de receita esperada, constitui-se num indicador de que o grau de prudência no endividamento foi diminuído. A elevação dos encargos financeiros leva a uma maior dependência do financiamento por parte das empresas endividadas, independentemente do nível das taxas de juros.

Com o período de expansão aumentam as necessidades de crédito e as tentativas de controle por parte das autoridades monetárias visando impor mecanismos de controle no relacionamento dos bancos com os seus clientes. Desse relacionamento resultam inovações financeiras, pois verifica-se um mútuo interesse entre tomadores e emprestadores. Neste sentido, a moeda não pode ser entendida, se não incorporadas sua evolução e as inovações. Fica evidenciado que a mesma é uma variável endogenamente determinada, sendo sua oferta uma resposta a demanda e não algo que possa ser controlado exogenamente pela Autoridade Monetária. $\mathrm{O}$ ativismo das instituições financeiras, manifestado através dos ajustes verificados nos itens ativos e passivos de seus portfólios, é responsável pela criação endógena de moeda. 
Com o ciclo de expansão, aumenta a imobilização do balanço das empresas não financeiras que, para cumprir os acordos financeiros, passam a depender do crédito de curto prazo, uma vez que as receitas correntes passam a ser insuficientes para cobrir os compromissos financeiros (ponzi). Os períodos de "boom" são caracterizados pela elevação do nível de endividamento, e é justamente o aumento percentual do estoque da dívida em relação ao saldo dos fundos próprios ou o aumento do serviço da dívida frente ao fluxo de receitas correntes, que pode reverter o ciclo expansionista.

$\mathrm{Na}$ busca de fundos, para honrar os compromissos financeiros, os devedores podem refinanciar suas dívidas, o que amplia o grau de dependência do mercado financeiro ou optar pela liquidação de ativos.

Se houver uma elevação da taxa de juros, as empresas não-financeiras com comportamento especulativo tentarão o refinanciamento pela via da venda de ativos, que, se generalizada, pode diminuir o preço dos ativos reais e provocar uma reversão de expectativas para as novas decisões de investimento. A queda do preço de demanda de ativos, incluindo a cotação das ações favorece as aquisições de controle acionário de plantas já existentes. Isto reverte as decisões de investimento, uma vez que os preços dos bens de capital já existentes em atividade, tornam-se menores que os preços de oferta de bens de capital.

Uma diminuição dos gastos em investimentos, com queda da de- manda efetiva, propicia o surgimento de deflação de débitos. Os recursos então disponíveis passam a ser utilizados no pagamento de dívidas ou também na aquisição de ativos mais líquidos. Esta preferência pela liquidez, na forma de moeda e quase moeda, decorre da avaliação subjetiva que os agentes fazem das composições dos passivos. Nesse processo de ajuste financeiro, as empresas não-financeiras procuram alongar o perfil de suas dívidas, buscando funding para trocar dívida de curto prazo por dívida de longo prazo.

A hipótese da instabilidade financeira de Minsky está apoiada no duplo aspecto da fragilidade financeira. Pelo lado do passivo, o encarecimento do serviço da dívida e sua necessidade de rolagem provocam pressão pela liquidação dos valores ativos. No lado do ativo, a diminuição dos lucros leva à deterioração da capacidade de honrar os débitos assumidos contratualmente.

\section{II - Contexto atual e a teoria de Minsky}

Os pressupostos teóricos de Minsky, expostos anteriormente, nos remetem a uma economia em que o processo de endividamento das empresas não-financeiras, para fazer frente sobretuto aos investimentos, se fazia junto ao sistema bancário, que era controlado pelo banco central. De acordo com tais pressupostos, o endividamento das empresas não-financeiras passava pela intermediação bancária. No entanto, mudanças verificadas principalmente a partir da década de 70, com a crescente internacionalização financeira, alteraram profundamente esse quadro.

$\mathrm{Na}$ década de 80 , a economia mundial foi afetada por flutuações no dólar, marco e iene, acompanhada de extrema volatilidade das taxas de juros. Essas flutuações com câmbio não fixo, que, supostamente, deveriam corrigir os desequilíbrios do balanço de pagamentos e permitir um maior grau de autonomia às políticas domésticas, se revelaram desestabilizadoras, uma vez que a crescente mobilidade dos capitais de curto prazo passou a obrigar intervenções na política monetária. Isto implicou em elevação das taxas de juros nas diferentes moedas, impondo sérias restrições à política fiscal.

A crise do sistema de crédito internacional e também a forma como os Estados Unidos enfrentaram o enfraquecimento do dólar (enquanto moeda internacional), propiciaram condições para que surgissem novas formas de intermediação financeira e uma outra etapa da globalização, com crescente generalização e supremacia dos mercados de capitais em detrimento do mercado de crédito anterior em que prevalecia a intermediação bancária.

Para Belluzzo \& Coutinho (1996:1) "a novidade nestes mercados de finanças 'securitizadas' é a participação crescente das famílias, como ofertantes de fundos e detentoras de papéis, através dos investidores institucionais (fundos de pensão, fundos mútuos e seguradoras). Na outra ponta, os emissores são basicamente os 
Tesouros Nacionais (com destaque para os EUA), grandes empresas e bancos. Diferente do que ocorreu no pós-guerra até o início dos anos oitenta, a transformação das poupanças em créditos bancários cedeu lugar à finança direta, mobilizada através de mercados ativos".

Nesta etapa da globalização financeira, com um mercado de dinheiro unificado em nível internacional, as empresas, quer sejam industriais ou financeiras podem contrair empréstimos ou aplicar em fundos sem limites e quando queiram, recorrendo aos diversos instrumentos existentes (PLIHON, 1995:61).

Na etapa atual, as finanças apresentam sua própria lógica, não tendo mais do que uma relação indireta com o funcionamento do intercâmbio e dos investimentos na economia mundial, passando a ser dominada por uma dinâmica especulativa, com uma parte importante das transações financeiras recebendo o impulso das antecipações quanto à evolução futura das transações. Os agentes que raciocinam num prazo mais curto nesse mercados são predominantes. Os operadores tendem a se abstrair da realidade dos fundamentos para buscar uma opinião sobre a tendência do mercado, segundo Plihon (1995:64) o desvio especulativo intervém porque os mercados tornamse mais voláteis e os investidores ficam sem referências, nas quais possam apoiar suas expectativas.

Um caso exemplar de lógica especulativa é o mercado de derivativos, cuja função deveria ser propiciar cobertura contra riscos de taxas de juro e câmbio. No entanto, além dos operadores que recorrem os derivativos com este fim, constam os especuladores, que atualmente realizam a maior parte desse tipo de transação.

Ao analisar as proposições teóricas de Minsky, podemos afirmar que sua abordagem avança em relação às proposições dos monetaristas clássicos e os partidários das expectativas racionais, ao incorporar a incerteza e as expectativas dos agentes. No entanto, se faz necessário ressaltar que as proposições do autor estão amplamente apoiadas na observação de um mercado com forte intermediação bancária, que prevaleceu até a década de 70 .

Minsky avança em relação as abordagens tradicionais por revelar as origens das fragilidade financeiras, elucidando como as oportunidade de lucros levam as empresas não-financeiras a sair de uma situação hedge para especulativas e chegando a Ponzi no processo de reversão do ciclo de expansão. Para o autor, as inovações financeiras ditadas pelas necessidades de financiamento das empresas no período de expansão fogem aos controles das Autoridades Monetárias, propiciando a criação de moeda endógena.

As proposições de Minsky apontam claramente para os determinantes de instabilidade presentes em uma economia monetária, com forte intermediação bancária, mas sua abordagem não avançou no sentido de incorporar as transformações verificadas a partir da década de 80 , quando passaram a predominar mercados altamente especulativos. Nestes mercados onde predominam uma economia de ativos na formação do patrimônio das famílias, empresas e bancos, as Autoridades Monetárias não podem permitir uma queda no preço desses ativos, sendo obrigadas a intervir, mas essas intervenções não podem ser com uma freqüência que agrave o chamado "moral Hasard", restando então para as Autoridades Monetárias, a opção de intervir para administrar as flutuações dos preços desses ativos, o que de certa forma limita o papel de supridor em última instância dos bancos centrais.

Os avanços da teoria de Minsky frente às teorias das expetativas racionais e do monetarismo clássico são bastante evidentes, sobretudo porque o autor não atribui qualquer função estabilizadora ou autocorretiva à especulação. Mas, se considerarmos as transformações verificadas a partir dos anos 80, poderemos verificar que os pressupostos teóricos de Minsky não incorporam certos aspectos do mercado financeiro, que se fazem presentes na fase mais recente do processo de internacionalização financeira.

No sentido de avanço, que contribui para a compreensão da dinâmica dos mercados financeiros atuais, se faz necessário destacar a contribuição de Soros (1987), com a teoria da reflexividade. Segundo esta teoria, "as situações que os agentes precisam entender para chegar às suas decisões são afetadas pelas próprias decisões" (COSTA, 1996:5). A realidade é alterada pelo comporta- 


\section{Bibliografia}

mento dos agentes, continuando incerta.

De acordo com Soros, a tendência para o equilíbrio, apontada pelas teorias convencionais, se mostra irrealista, uma vez que, os mercados flutuam continuamente, numa seqüência assimétrica de boom e crise, com aceleração vagarosa e reversão catastrófica. A tendência dos participantes do mercado é um elemento de determinação dos preços dos ativos, mas em conformidade com sua teoria da (reflexividade), todo movimento importante dos preços afeta a tendência dos participantes.

Para Costa (1996:15) "os processos reflexivos tendem a seguir determinado padrão, em que uma tendência, de início auto-reforçadora, se torna cada vez mais vulnerável, porque fundamentos como comércio exterior e pagamentos de juros internacionais se movem contra si. Quando a realidade não consegue mais corresponder as expectativas e cada vez mais especuladores percebem o "erro" em que repousa o boom, alcança-se o ponto critico e um processo de auto-reforçamento começa a operar na direção oposta”.

Embora Minsky não tenha abordado os processo reflexivos, apresentou elementos que nos permitem compreender os processos de instabilização financeira. No entanto, temos que reconhecer, como economista está atrasado em relação à realidade econômica e financeira.
BELLUZZO, Luís G.M. O Declínio de Bretton Woods e a Emergência dos Mercados "Globalizados". Economia \& Sociedade, vol. 4, Campinas, 1995.

BELLUZZO, Luís G. M. \& COUTINHO, Luciano G. Estabilização e Finanças "Globalizadas”, mimeo, Campinas, 1996.

CAPORALE MADI, M. A. Política Monetária no Brasil: uma interpretação pós-keynesiana. Tese de Doutoramento, Campinas, 1993.

COSTA, Fernando N. da. Gestão Monetária sob Condições de Globalização, Desintermediação e Reflexividade, mimeo, Campinas, $1996^{\mathrm{a}}$.

\section{Por Uma Teoria Al-} ternativa da Moeda. Campinas, Tese de Livre Docência, 1994.

. Incerteza, Preferência por Liquidez e Instabilidade, Ensaios de Economia Monetária, Bienal, 1992.

. Mecanismo de Transmissão Monetária: interação e iteração. Economia \& Sociedade, vol. 5 Campinas, 1995.

COUTINHO, Luciano G. Notas Sobre a Natureza da Globalização. Economia \& Sociedade, vol. 4, Campinas, 1994.
FERREIRA, Carlos K. L. O Financiamento da Indústria e Infraestrutura no Brasil: crédito de longo prazo e mercado de capitais. Tese de Doutoramento, Campinas, 1995.

MINSKY, Hyman. STABILIZING an Unstable Economy, New Havem. Yale University Press,1986.

PHIHON, Dominique. A Ascensão das Fianças Especulativas. Economia \& Sociedade, vol. 5, Campinas, 1995.

SOROS, George. A Alquimia das Finanças, Nova Fronteira, Rio de Janeiro, 1996. 